\title{
Dramatizing 1Malaysia in contemporary Chinese lion dance
}

\begin{abstract}
This article looks into the evolution of the diasporic Chinese lion dance in Malaysia. More importantly, it examines how this traditional art genre stands out among the many other forms that have withstood extinction. Although once regarded as foreign to the national culture in Malaysia due to its identity as a Chinese folk art, it was first threatened, but not abandoned. Malaysia eventually responded by merging the northern and southern lion styles and developing a World Lion Dance Championship. This article will elaborate on the origin of the lion dance, and examine changes that may be factors in its sustainability. More importantly, the article examines the political concept of 1Malaysia introduced by Prime Minister DatoôSri Haji Mohammad Najib Tun Haji Abdul Razak in 2008 that has brought a new model to the lion dance in aiming for national unity. Kun Seng Keng Dragon and Lion Dance Troupeô practice exemplifies this phenomenon.
\end{abstract}

Keyword: Chinese lion dance; 1Malaysia 